\title{
FEBRILE INFECTION-RELATED EPILEPSY SYNDROME: A RARE CASE PRESENTATION
}

\author{
ALOYSIUS JAMES, RESHMA REJI, BINI VINCENT, NIMMU MANI, REMYA REGHU*
}

Department of Pharmacy Practice, Amrita School of Pharmacy, Amrita Vishwa Vidyapeetham, Amrita University, Kochi - 682 041, Kerala, India. Email: remyareghu@aims.amrita.edu

Received: 05 November 2016, Revised and Accepted: 30 November 2016

ABSTRACT

Febrile infection-related epilepsy syndrome is characterized by super refractory status epilepticus that is resistant to conventional antiepileptic drugs. This case report critically analyses the treatment options adopted in a hospital to manage this syndrome. Despite the aggressive efforts that were taken, the patient succumbed to the complications of the illness and side effects of the treatment strategies adopted. This shows that the treatment options currently available are in adequate, so an intensive research in the area of pathogenesis of status epilepticus is required to frame treatment strategies that can bring out better outcomes.

Keywords: Antiepileptics, Febrile infection-related epilepsy syndrome, Status epilepticus.

(C) 2017 The Authors. Published by Innovare Academic Sciences Pvt Ltd. This is an open access article under the CC BY license (http://creativecommons. org/licenses/by/4. 0/) DOI: http://dx.doi.org/10.22159/ajpcr.2017.v10i3.16045

\section{INTRODUCTION}

Febrile infection-related epilepsy syndrome (FIRES) is an acute onset epileptic encephalopathy in which previously healthy children present with prolonged treatment becomes resistant status epilepticus $[1,2]$. The clinical profile consists of an initial phase of febrile infection, followed by an acute phase marked by recurrent seizures (partial or secondary generalized seizures, facial myoclonus) during which the fever resolves. In the chronic phase survivors present with drug resistant epilepsy and neuropsychological impairment. Mortality rate in the acute phase is about $30 \%$. Treatment requires polytherapy (on an average 6 antiepileptic drugs [AEDs] per patient). Early placement of patients on ketogenic diet might optimize seizure control and cognitive outcome after FIRES. The significant role of immunotherapy has not been proven $[3,4]$.

\section{CASE REPORT}

A 11-year-old female child, with no significant history of neurological disorder, was admitted with case of status epilepticus following a period of febrile illness 3 weeks back. Shortly after the onset of fever she had developed abnormal behavior in the form of poor responsiveness and further developed seizures. Later the frequency of seizures increased and was admitted in the local hospital and evaluated. Magnetic resonance imaging (MRI) brain showed linear horizontal enhancing vessel extending from subependymal location of frontal horn suggestive of vascular malformation, venous angioma, occult cryptic vascular malformation with no evidence of obvious encephalitis or meningitis. Electroencephalography (EEG) showed bilateral temporo-occipital and temporal spikes. Other investigations done locally were shown in Table 1.

While at the local hospital she had multiple episodes of seizure. She was started on mannitol, antibiotics (tablet septran [sulfamethoxazole 400 mg+trimethroprim $80 \mathrm{mg}$ ]), and antivirals (acyclovir $250 \mathrm{mg}$ ) there. A course of intravenous (IV) immunoglobulins (Ig) and steroids were also given. However she developed status epilepticus, she was ventilated and started on midazolam (10 mg/10 ml) infusion apart from AEDs (tablet eptoin $100 \mathrm{mg}$, phenobarbitone $60 \mathrm{mg}$, tablet phenytoin $100 \mathrm{mg}$, tablet levipil $100 \mathrm{mg}$, tablet clonazapam $1 \mathrm{mg}$, tablet lacosamide $50 \mathrm{mg}$, tablet frisium $5 \mathrm{mg}$, and tablet valparin $500 \mathrm{mg}$ ) and was referred to our hospital which is tertiary care referral center. On admission she was on ventilation, in view of recurrent seizures AEDs were optimized and titrated as per clinical requirement. MRI brain showed mild leptomeningeal enhancement especially involving bilateral superior fronto parietal. Antibiotics were started as per available culture sensitivity report. Supportive treatment in the form of blood product transfusion and electrolytes were given. In view of super refractory seizures, she was started on thiopentone infusion $1 \mathrm{~g}$, injection fosphenytoin sodium $150 \mathrm{mg} / 2 \mathrm{ml}$, injection phenobarbitone $200 \mathrm{mg}$, tablet clonazepam $2 \mathrm{mg}$, injection levipil $500 \mathrm{mg} / 5 \mathrm{ml}$ and which was gradually tapered. She was on multiple AEDs. She was given two cycles of plasmapheresis. Tracheostomy was done in view of need of prolonged ventilation. IV antibiotics (meropenem $500 \mathrm{mg}$, colistimethate sodium $1,000,000 \mathrm{IU}$ ) were given as per c/s report. She was continued on AEDs and ketogenic diet. She was gradually weaned from bilevel positive airway pressure (BiPAP) but developed sudden asystole without prior desaturation or tachypnea and revived with resuscitative measures. Her ECHO done was normal. She developed bed sores for which plastic surgery consultation was taken. Debridement and exploration was done for the nonhealing bed sores. Later developed bleeding from debridement site and had altered coagulation parameters which were managed appropriately. In view of hypoalbuminemia and nonhealing ulcers her diet was changed from ketogenic diet to high protein diet. She had minor seizures during her hospital stay and EEG showed left parieto temporo-occipital epileptiform abnormalities. Follow-up EEG were done and her AEDs were stepped down. IV Albumin was given for 3 days in view of hypoalbuminemia, 1 pint packed red blood cells was transfused in view of low Hb. Gradually her ventilator requirements were weaned down and BiPAP was started. Off BiPAP trials were given, but in view of tracheostomy leak, it was changed. Her serum phenobarbitone and eptoin levels were within normal limits. Nerve conduction velocity showed evidence for predominantly axonal type of sensory motor neuropathy affecting both lower limb more than upper limb and most probably suggestive of critical illness neuropathy. She was on antibiotics for bloodstream associated infection. Need for ventilation during BiPAP weaning trials has been explained in detail to her parents. Progress showed for few days. In spite of intensive care, she had a cardiorespiratory arrest and was not revived as per the wishes of family.

\section{DISCUSSION}

Children with FIRES get frequent focal seizures immediately after a febrile infection. These seizures develop rapidly to status epilepticus 
Table 1: Investigations done

\begin{tabular}{lc}
\hline CSF study & Normal \\
\hline Serum leptospira & Negative \\
Widal test & Negative \\
HSV PCR & Negative \\
Anti-NMDAR & Negative \\
Anti-VGKC & Negative \\
ANA profile & Negative \\
ACE (sarcoidosis) & Negative \\
Dengue (IgM antibody) & Negative \\
\hline CSF: Cerebrospinal fluid, HSV-PCR: Herpes simplex virus-polymerase chain
\end{tabular}

CSF: Cerebrospinal fluid, HSV-PCR: Herpes simplex virus-polymerase chain

reaction, ANA: Antinuclear antibodies, IgM: Immunoglobulins M

which is pharmacoresistant and persist for several weeks to months. Survivors of acute phase progress into chronic phase results in pharmacoresistant status epilepticus and significant cognitive impairment $[1,3-5]$. The refractory seizures continue to occur despite treatment with multiple AEDs.

The largest, multicenter review in this area included 77 children. The acute mortality rate was $11.7 \%$ and $93 \%$ of the survivors had refractory status epilepticus. Only $18 \%$ of the survivors were cognitively normal. $16 \%$ had borderline cognition, $14 \%$ had mild mental retardation, $24 \%$ had moderate mental retardation and $12 \%$ had severe mental retardation, and $16 \%$ were in a vegetative state [4]. Death may occur in most refractory cases.

Therapy with benzodiazepines is given in early status epilepticus (IV midazolam/IV or rectal diazepam). IV antiepileptics are preferred in established status epilepticus. If seizures continue to persist for up to $2 \mathrm{hrs}$, despite the above treatment, then general anesthesia is recommended where dosing is based on EEG burst suppression approach (thiopental/pentobarbital/midazolam). This approach is associated with declining cognitive status. Anesthesia is recommended to prevent excitotoxicity. The disadvantage of anesthesia is hypotension, cardiorespiratory depression, and development of acute tolerance. Pentobarbital follows zero order kinetics, so it has a tendency to accumulate and prolong recovery phase [6,7]. Although the effectiveness of AEDs has not been clearly established in super refractory status epilepticus, it is a conventional practice to administer antiepileptics along with anesthesia. The AEDs conventionally used are carbamazepine, lacosamide, levetiracetam, phenobarbital, phenytoin, topiramate, and valproate. However, there is no evidence that any of these is less or more effective than other [8]. The recognition that super refractory status epilepticus may be due to antibodies directed against neural elements and that inflammation plays an important role in epileptogenesis have led to potential use of steroid and immunotherapy. However there are no clear guidelines about dose, duration of therapy, and evaluation of effectiveness. Steroids are associated with gastrointestinal ulceration, sodium and fluid retention, and psychiatric disturbances. Major adverse effects of Ig are coagulation disorders and hypertension [9-11]. Early ketogenic diet treatment, especially during acute phase, may optimize both seizure control and cognitive outcomes in FIRES [4]. Ketogenic diet is associated with acidosis, constipation, hypoglycemia, and hypercholesterolemia. The successful use of magnesium infusion and hypothermia in status epilepticus has also been reported $[12,13]$.

\section{CONCLUSION}

The etiology of FIRES has not been clearly defined. Optimum seizure control is not obtained using conventional multiple AEDs. Clear knowledge about the underlying pathophysiology is required to frame treatment strategies. Several hypotheses have been put forward and the scope for future research in this area is huge. A child with refractory seizures requires the care of a highly skilled team with expertise in pediatric intensive care, neurology, epileptology, nursing, pharmacy, and dietitian.

\section{REFERENCES}

1. Mikaeloff Y, Jambaqué I, Hertz-Pannier L, Zamfirescu A, Adamsbaum C, Plouin P, et al. Devastating epileptic encephalopathy in school-aged children (DESC): A pseudo encephalitis. Epilepsy Res 2006;69(1):67-79.

2. van Baalen A, Stephani U, Kluger G, Häusler M, Dulac O. FIRES: Febrile infection responsive epileptic (FIRE) encephalopathies of school age. Brain Dev 2009;31(1):91

3. van Baalen A, Häusler M, Boor R, Rohr A, Sperner J, Kurlemann G, et al. Febrile infection-related epilepsy syndrome (FIRES): A nonencephalitic encephalopathy in childhood. Epilepsia 2010;51(7):1323-8.

4. Kramer U, Chi CS, Lin KL, Specchio N, Sahin M, Olson H, et al. Febrile infection-related epilepsy syndrome (FIRES): Pathogenesis, treatment, and outcome: A multicenter study on 77 children. Epilepsia 2011;52(11):1956-65.

5. Nabbout R, Vezzani A, Dulac O, Chiron C. Acute encephalopathy with inflammation-mediated status epilepticus. Lancet Neurol 2011;10(1):99-108

6. Kramer U, Chi CS, Lin KL, Specchio N, Sahin M, Olson H, et al. Febrile infection-related epilepsy syndrome (FIRES): Does duration of anesthesia affect outcome? Epilepsia 2011;52 Suppl 8:28-30.

7. Jackson JH. Remarks on the diagnosis and treatment of diseases of the brain. Br Med J 1888;2(1437):59-63.

8. Towne AR, Garnett LK, Waterhouse EJ, Morton LD, DeLorenzo RJ. The use of topiramate in refractory status epilepticus. Neurology 2003;60(2):332-4

9. Vezzani A, Balosso S, Aronica E, Ravizza T. Basic mechanisms of status epilepticus due to infection and inflammation. Epilepsia 2009;50 Suppl 12:56-7.

10. Vezzani A, Rüegg S. The pivotal role of immunity and inflammatory processes in epilepsy is increasingly recognized: Introduction. Epilepsia 2011;52 Suppl 3:1-4

11. Maroso M, Balosso S, Ravizza T, Liu J, Aronica E, Iyer AM, et al. Tolllike receptor 4 and high-mobility group box-1 are involved in ictogenesis and can be targeted to reduce seizures. Nat Med 2010;16(4):413-9.

12. Fisher RS, Kaplan PW, Krumholz A, Lesser RP, Rosen SA, Wolff MR. Failure of high-dose intravenous magnesium sulfate to control myoclonic status epilepticus. Clin Neuropharmacol 1988;11(6):537-44.

13. Orlowski JP, Erenberg G, Lueders H, Cruse RP. Hypothermia and barbiturate coma for refractory status epilepticus. Crit Care Med 1984;12(4):367-72. 